Vol. 1, No. 2, Desember 2020

SPEKTA

Jurnal Pengabdian Kepada Masyarakat : Teknologi dan Aplikasi

Journal homepage :

http://journal2.uad.ac.id/index.php/spekta

\title{
APLIKASI TEKNOLOGI PLTMH TURBIN PROPELLER OPEN FLUME SEBAGAI PEMBANGKIT LISTRIK DESA
}

Aris Suryadi", Mochamad Faisal, Berayan Munthe, Mindit Eriyadi, Junaidy Burhan

Politeknik Enjinering Indorama, Kembang Kuning-Jatiluhur, Purwakarta, Jawa Barat, Indonesia.

\section{INFO ARTIKEL}

Diterima: 2 September, 2020

Direvisi: 19 September, 2020

Disetujui: 25 September, 2020

Keywords:

Turbine Rotation;

Propeller;

Open Flume.

\begin{abstract}
Berecek Village, located in Sukatani District, Purwakarta Regency, West Java Province, has a river that has not been used optimally. This community service aims to utilize the available water energy so that it can produce Micro Hydro power plants. The manufacture of a micro-hydro power plant starts from measuring water potential, designing turbines and generators, then observing the work system and estimating the electrical power that will be generated. From the survey results, it is known that the water discharge is $0.0059 \mathrm{m3} / \mathrm{s}$ and has a fall height of $4 \mathrm{~m}$. This data is used to select the type of turbine, reservoir selection, quick pipe, and generator design. The results of the manufacture of micro power plants obtained by designing using an open flume propeller turbine with a turbine rotation speed of 2,063 rpm, this PLTMH is able to produce turbine power of 1,346 watts with a water discharge of 45 liters / second so that the power obtained is 1,076 watts.
\end{abstract}

\section{PENDAHULUAN}

Energi listrik merupakan kebutuhan masyarakat baik perkotaan maupun pedesaan. Apabila pada suatu daerah sebagian pedesaan yang belum tersentuh jaringan listrik, tentunya menjadi suatu permasalahan dimasyarakat desa itu sendiri. Kampung Berecek yang terletak di Desa Sukatani, Kabupaten Purwakarta yang keberadaan lokasi pada jalan desa tersebut belum dilengkapi dengan penerangan. Aktivitas warga hanya terbatas pada pagi dan siang hari, dimana apabila menjelang malam tentunya mobilisasi warga terbatas dikarenakan tidak adanya penerangan jalan. Perlu adanya solusi yang tepat guna yang

\footnotetext{
* Corresponding author.

E-mail address: aris.suryadi@ pei.ac.id

https://doi.org/10.12928/spekta.v1i2.2742
} 
nyata, dengan adanya pembangkit listrik tenaga mikro hidro (PLTMH) sebagai sumber listrik. Potensi yang terdapat pada desa ini adanya aliran sungai yang mengalir untuk mencukupi irigasi pertanian dan memungkinkan pula dapat bermanfaat sebagai pembangkit listrik.

Dengan memanfaatkan aliran sungai yang memiliki jatuh air yang bernilai di bawah $50 \mathrm{~m}$, tentunya dapat memutarkan turbin sebagai tenaga penggeraknya dengan memiliki kapasitas generator sebesar $1 \mathrm{~kW}$ sampai $100 \mathrm{~kW}$ (Suryadi, 2015). Proses pembangkitan listrik dilakukan dengan memutar generator sehingga dihasilkan tegangan listrik bolakbalik. Diperlukan energi mekanik untuk memutar generator umumnya disebut penggerak mula (Suryadi, 2017).

Pembuatan pembangkit tenaga mikro hidro sebagai pembangkit listrik yang dilaksanakan di kampung Berecek dilakukan dengan tahapan perancangan dan pemilihan turbin bertujuan untuk menerapkan turbin air jenis Propeller Open Flume sebagai Prime Mover, energi yang telah dilakukan survei sebesar 59,25 liter/detik dan ketinggian air jatuh efektif 4 meter. Turbin propeller open flume merupakan turbin reaksi yang dapat beroperasi pada head rendah kurang dari 6 meter, memiliki konstruksi sederhana dan harga yang relatif murah (Suryadi, 2020).

\section{METODE PELAKSANAAN}

Metode pelaksanaan tentang perancangan pembangunan PLTMH di kampung Berecek serta pengaplikasian menggunakan turbin propeller open flume. Pada perancangan dibagi menjadi dua bagian, yaitu perancangan kontruksi bangunan dan perancangan kontruksi turbin.

Proses pembuatan pembangkit ini yang pertama adalah memulai dan melakukan studi literatur yaitu untuk mendapatkan informasi mengenai teori-teori dasar sebagai sumber pembuatan dan penulisan jurnal pengabdian masyarakat. Membaca dan mempelajari jurnal tentang Pembangkit Listrik Tenaga Mikro Hidro. Survey dan pengumpulan data dilakukan untuk mengetahui lokasi yang strategis untuk dibuatkan pembangkit listrik tenaga mikro hidro.

Perhitungan debit air dan pengukuran tinggi jatuh air dilakukan untuk mengetahui seberapa besar kapasitas daya yang akan dibangkitkan dan tipe turbin. selanjutnya adalah menganalisa kapasitas daya yang akan dibangkitkan dari hasil perhitungan debit air dan pengukuran tinggi jatuh air. Apabila dari hasil analisa berpotensi membangkitkan daya listrik maka tahapan selanjutnya yaitu perancangan alat.

Perancangan alat ini meliputi pemilihan tipe turbin (Joni, 2016) dan generator yang akan digunakan beserta perancangan kontruksi bangunan yang akan diterapkan pada proyek pembangkit listrik tenaga mikro hidro (Afryantima dan Syukri, 2015). Pengujian alat dilakukan untuk mengetahui apakah alat dapat berfungsi dengan baik atau tidak, apabila tidak berfungsi maka harus melakukan perbaikan ulang alat maupun kontruksi bangunan dan apabila berfungsi dengan baik maka dilanjutkan dengan melakukan analisa kapasitas daya (Yohannes, 2015). 
Vol. 1, No. 2, Desember 2020

Analisa kapasitas daya meliputi putaran turbin, putaran generator, tegangan, arus dan daya yang dikeluarkan oleh generator, serta daya konsumsi beban (Amsary, 2017). Penjelasan lebih lanjut mengenai alur metode pengabdian masyarakat ini dapat dilihat pada gambar 1 di bawah ini.

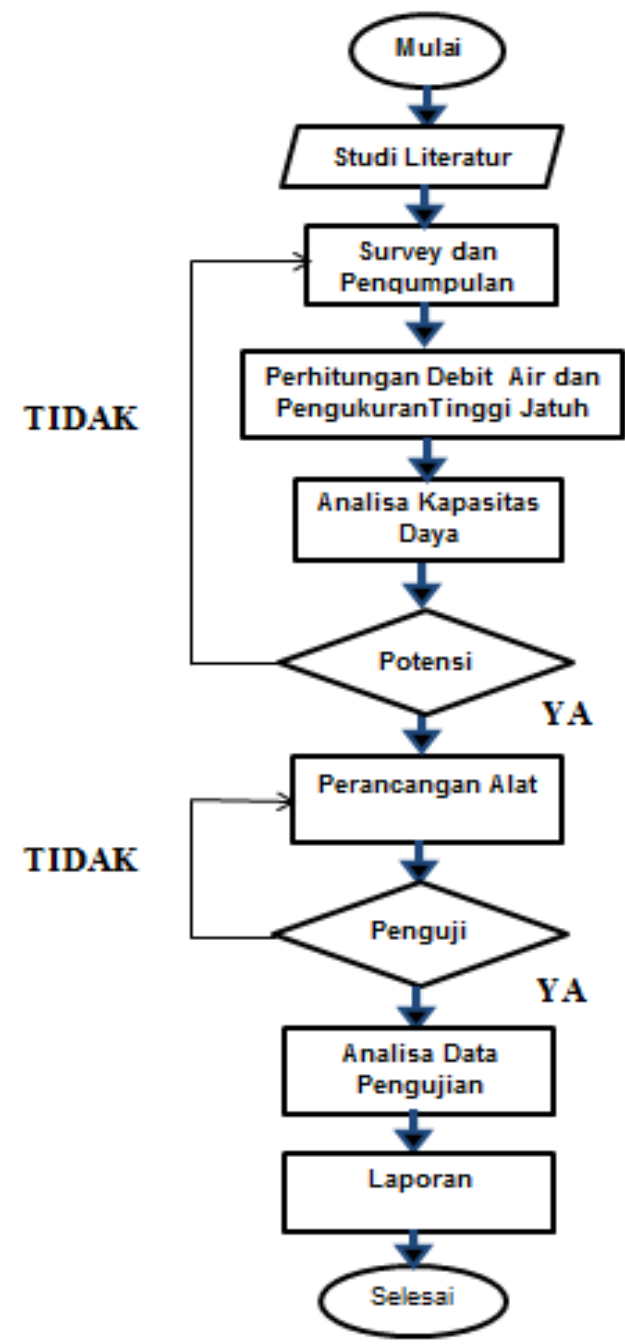

Gambar 1 Diagram Alur Pembuatan Pembangkit Listrik Desa

Energi potensial air mengalir masuk ke turbin kemudian turbin berputar menghasilkan energi mekanik, turbin yang dihubungkan pada generator dengan menggunakan $V$-belt menghasilkan energi listrik kemudian masuk ke panel kontrol dan proteksi kemudian energi listrik masuk ke beban resistif dan beban konsumen, kapasitas ballast load harus sama dengan generator dikarenakan untuk menampung daya yang tidak terpakai oleh beban, karena ketika beban melebihi kapasitas maka akan terjadi trip dan daya secara otomatis akan berpindah ke beban resistif (Cihanjuang Inti Teknik, 2018).

Adapun blok diagram prinsip kerja sistem PLTMH secara keseluruhan dapat dilihat pada gambar 2. Energi potensial air yang dapat dimanfaatkan sebagai penggerak turbin 
Vol. 1, No. 2, Desember 2020

propeller open flume yang terhubung dengan generator yang akan menghasilkan listrik. Pada pengontrolan generator diperlukan panel kontrol yang berfungsi untuk mengontrol tegangan dan air yang akan didistribusikan ke bebabn konsumen berupa penerangan jalan. Dilengkapi juga dengan pengaman atau proteksi pada generator yang berguna untuk melindungi generator dari beban lebih dengan dipasangkan berupa beban resistif.

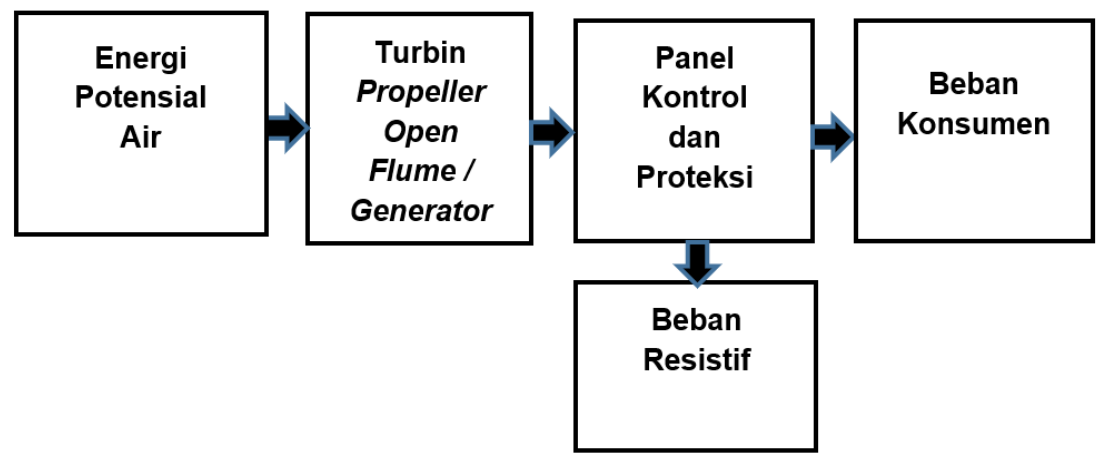

Gambar 2 Blok Diagram Prinsip Kerja Sistem PLTMH

Adapun pembangunan pada pembangkit listrik di Desa Berecek sebagai berikut :

Kondisi sungai yang berpotensi untuk dibangunkan bendungan yang merupakan suatu pembatas pada lintasan sungai untuk mengubah karakteristik sungai. Adapun ukuran bendungan yang telah dibuat adalah $1000 \mathrm{~cm}$ x $55 \mathrm{~cm}$ x $40 \mathrm{~cm}$ terlihat pada gambar 3 .

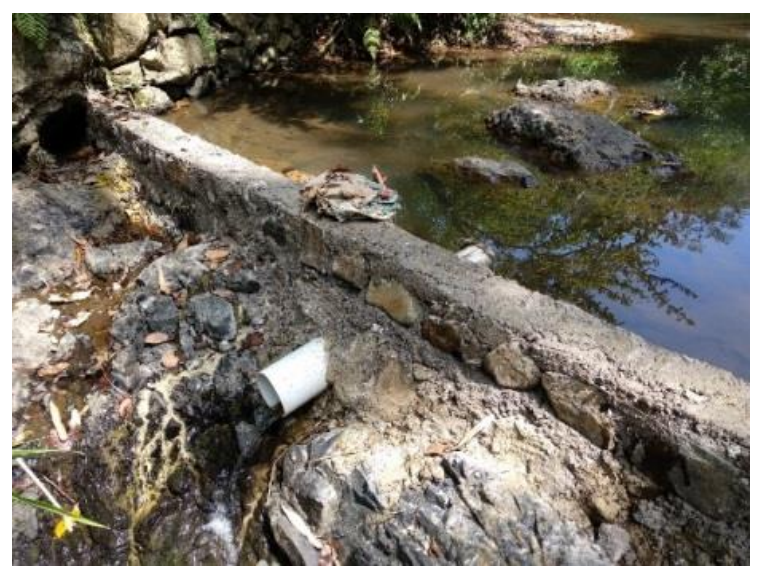

Gambar 3 Bendungan

Konstruksi kedua adalah saluran irigasi yang merupakan saluran penghantar air pada aliran air menuju bak kontrol dan bak turbin dengan ukuran $420 \mathrm{~cm}$ x $100 \mathrm{~cm}$ x $40 \mathrm{~cm}$. Berikut gambar 4 merupakan saluran irigasi yang telah dibangun. 


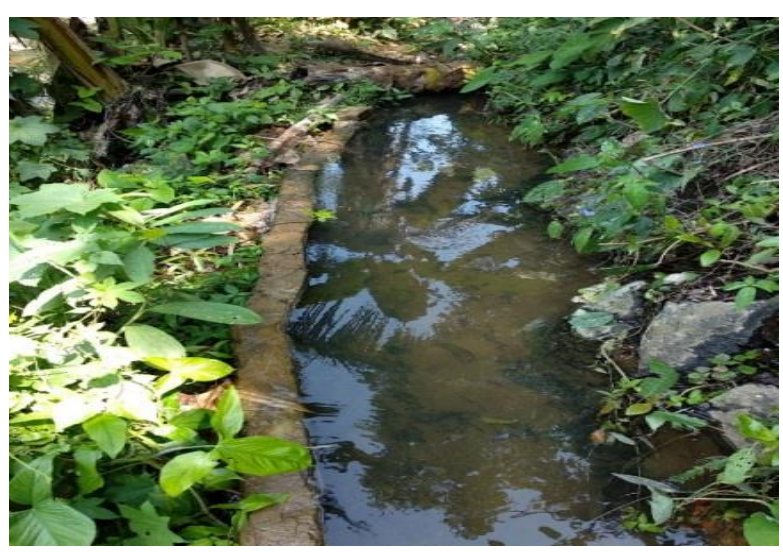

Gambar 4 Saluran Irigasi

Konstruksi ketiga adalah bak kontrol yang berfungsi sebagai pengontrol debit aliran air yang akan masuk ke saluran turbin. Berikut gambar 5 merupakan bak kontrol yang telah dibangun.

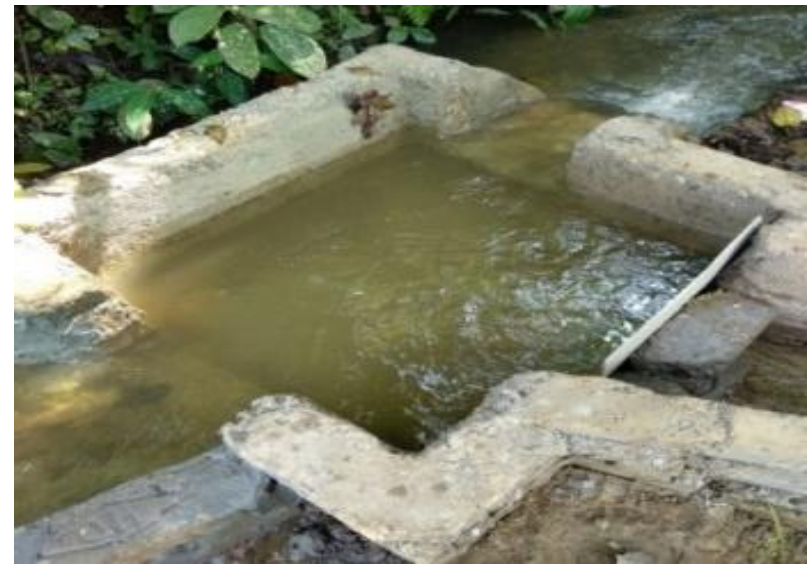

Gambar 5 Bak Kontrol

Konstruksi keempat adalah bak turbin yang berfungsi sebagai penampung air sebelum masuk ke dalam turbin dan pipa penstok, kontruksinya dibuat melingkar seperti rumah siput yang berguna agar air mengalir yang masuk ke dalam turbin menjadi teratur dan sesuai. Terlihat pada gambar 6 merupakan bak turbin yang telah dibangun.

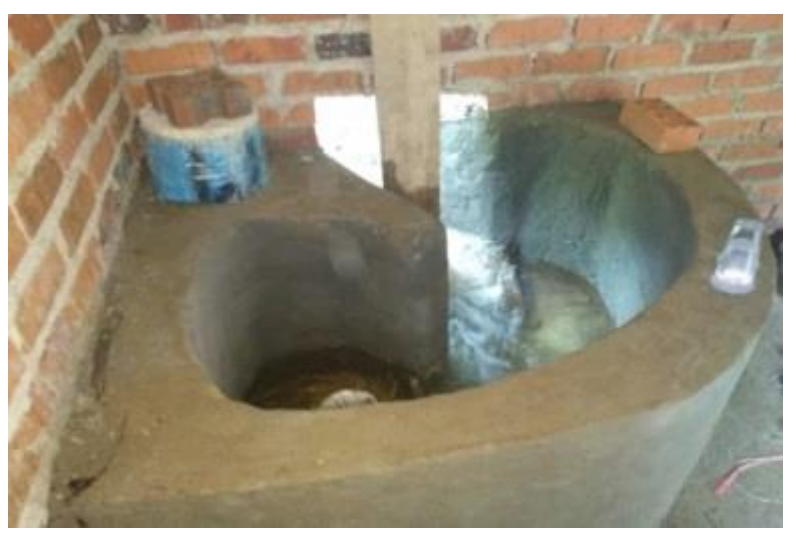

Gambar 6 Bak Turbin 
Vol. 1, No. 2, Desember 2020

Konstruksi kelima adalah pipa penstok dan tail race yang berfungsi sebagai menghisap air yang akan di proses pada turbin Konstruksinya harus diperhitungkan agar dapat menghisap air dan menghasilkan daya hisap yang tinggi, Tempat keluarnya air setelah menggerakkan turbin dan diteruskan ke aliran sungai dinamakan tail race. Untuk mendapatkan head static merupakan selisih ketinggian permukaan air dengan ketinggian tail race (Suryadi, 2015). Terlihat pada gambar 7 merupakan pipa penstok dan tail race yang telah terpasang.

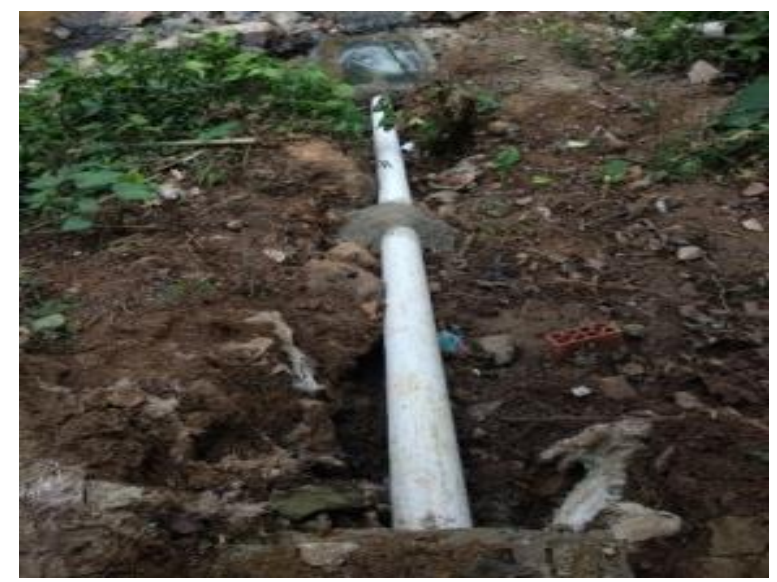

Gambar 7 Pipa Penstok

Konstruksi ke-enam adalah pembangunan untuk rumah pembangkit yang merupakan ruang instalasi turbin air, peralatan bantu, dan kontrol generator. Terlihat pada gambar 8 merupakan rumah pembangkit yang telah dibangun.

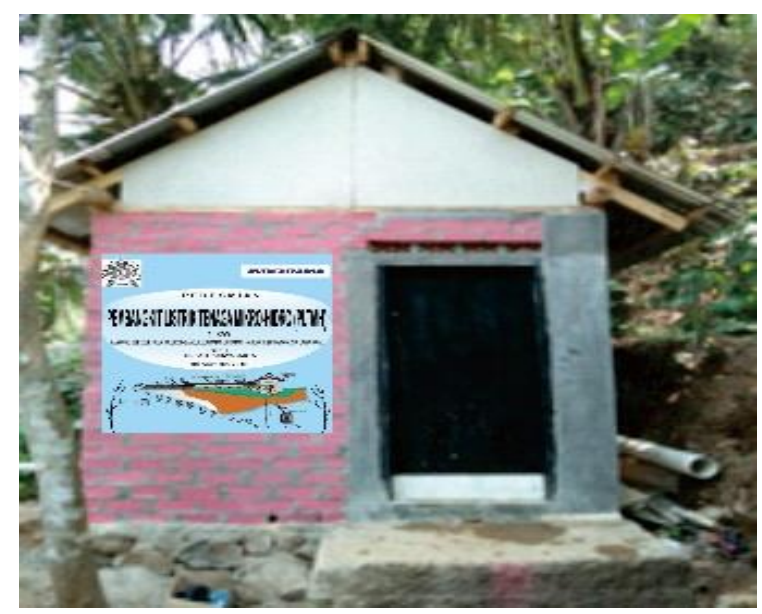

Gambar 8 Rumah Pembangkit

Kemudian konstruksi turbin yang terlihat pada gambar 9 desain kontruksi Turbin Propeller Open Flume secara keseluruhan. 

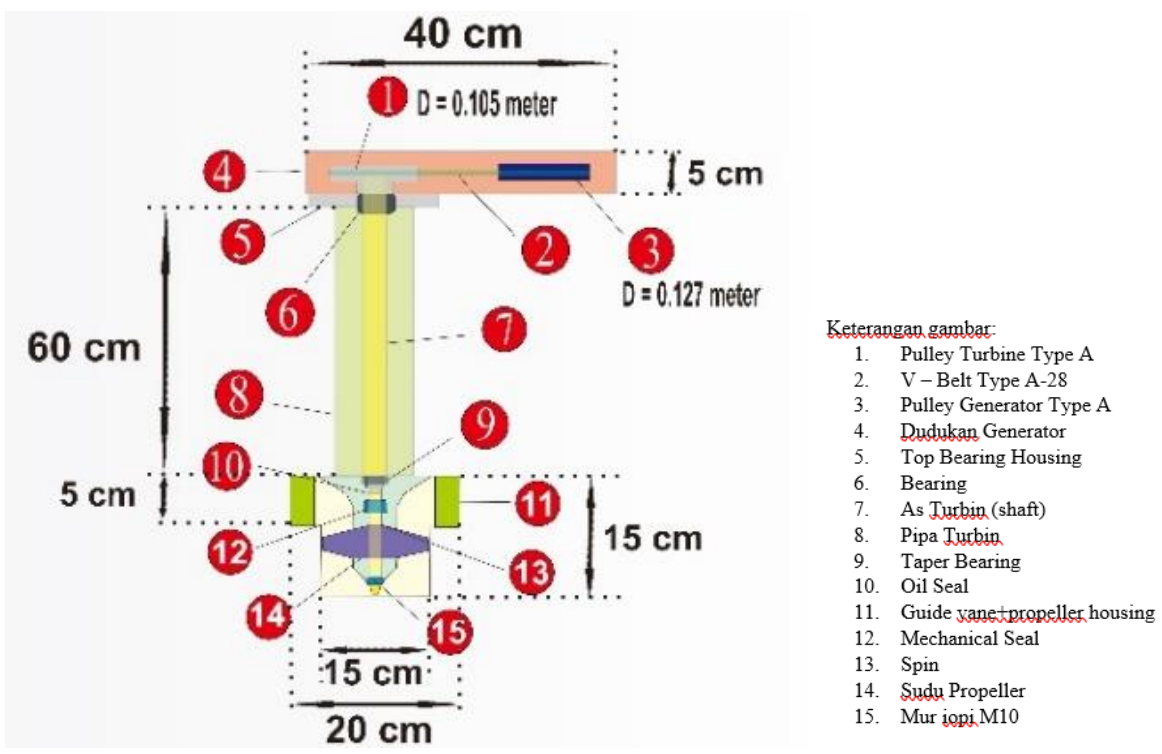

Gambar 9 Kontruksi Turbin Propeller Open Flume (Cihanjuang Inti Teknik, 2018)

Pada gambar 10 diperlihatkan bentuk sudu pengarah dari turbin propeller open flume yang merupakan penggerak utama pada generator $1 \mathrm{~kW}$. Turbin ini memiliki 6 sudu dengan berdiameter $150 \mathrm{~mm}$ dengan derajat kemiringan 30 serta putaran yang dihasilkan searah dengan arah jarum jam.

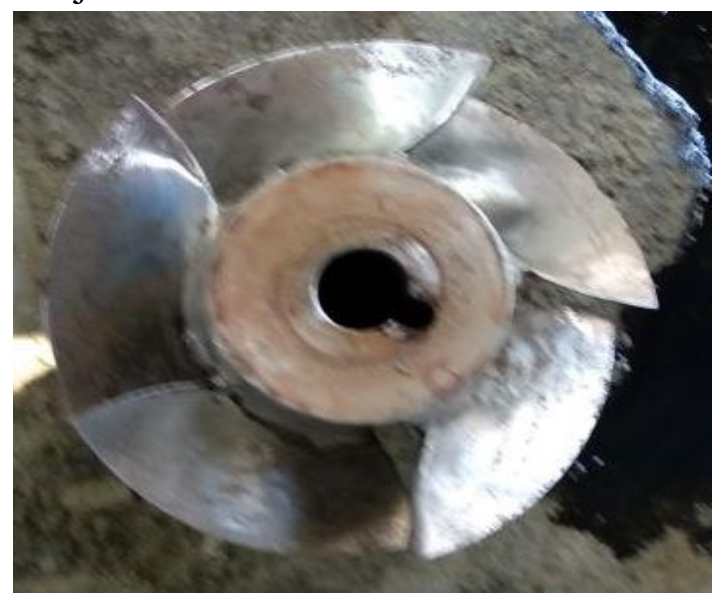

Gambar 10 Turbin Propeller Open Flume

\section{HASIL DAN PEMBAHASAN}

Hasil pengujian atas perancangan turbin propeller open flume yang telah dibuat, dilakukanlah pengujian yang bertujuan untuk mengetahui apakah alat yang dibuat sudah berjalan dengan baik seperti yang direncanakan ataupun belum (Dwiyanto, 2016), (Wibowo, 2015). Kesesuaian sistem dengan perencanaan dapat dilihat dari hasil-hasil yang dicapai pada pengujian alat (Akhmad, 2015).

Pengujian juga bertujuan untuk mengetahui kelebihan dan kekurangan dari alat yang telah dibuat. Bentuk fisik turbin propeller open flume yang telah terpasang dengan generator AC dapat dilihat pada gambar 11. 


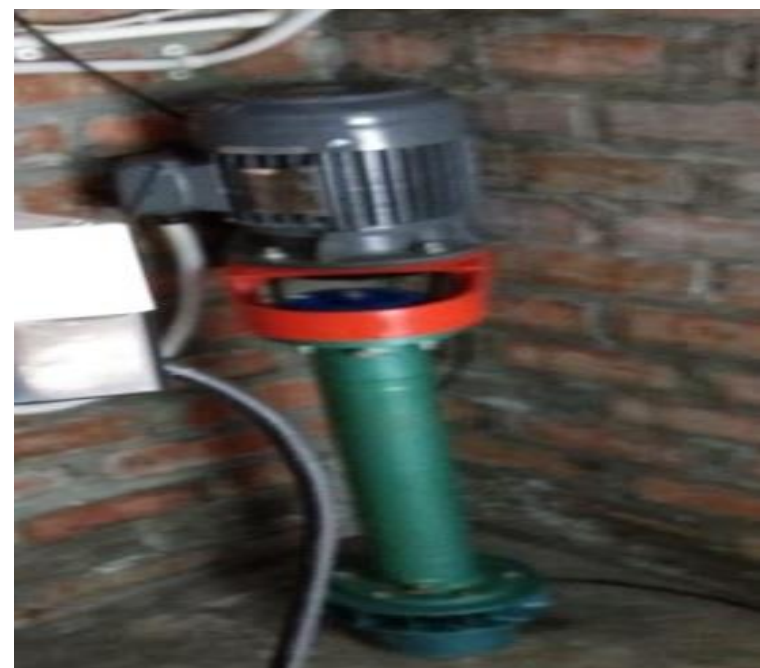

Gambar 11 Turbin Propeller Open Flume dengan Generator AC (Suryadi, 2020)

Setelah pengujian pembangkit telah sesuai yang diharapkan, maka dilaksanakanlah serah terima pembangkit PLTMH $1 \mathrm{~kW}$. Terlihat pada gambar 12 disaat peresmian dan serah terima pembangunan pembangkit PLTMH $1 \mathrm{~kW}$ kepada masyarakat kampung Berecek yang sebelumnya jalan desanya tidak memiliki penerangan dimalam hari.

Kini masyarakat desa tersebut telah dapat menikmati dari hasil pengabdian masyarakat yang telah dilakuakan oleh Politeknik Enjinering Indorama, Purwakarta. Mobilisasi warga dapat dilakukan dimalam hari, yang biasanya hanya terbatas menjelang pukul 06.00 sore saja. Pada gambar 12 terlihat acara penyerahan hibah sekaligus peresmian penggunaan pembangkit listrik yang disaksikan oleh Kepala Dinas Pemberdayaan Masyarakat Desa, Purwakarta tanggal 28 agustus 2018.

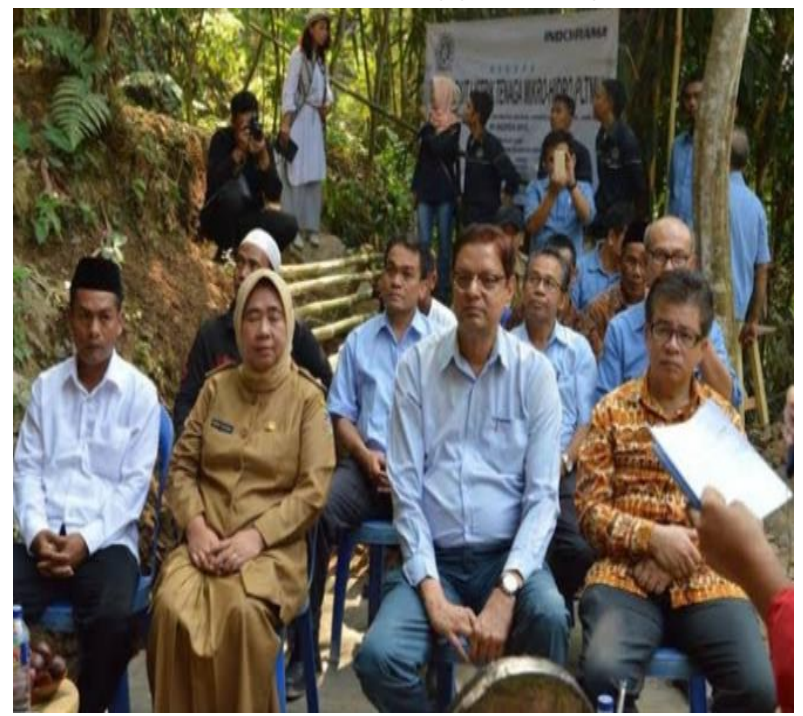

Gambar 12 Peresmian Penggunaan PLTMH dilakukan oleh Pemda Purwakarta

\section{KESIMPULAN}

Teknologi turbin propeller open flume merupakan pemanfaatan energi potensial air dan hisapan dari pipa penstok dengan ketinggian head 4 meter untuk dapat menghasilkan 
energi mekanik. Proses konversi energi dimulai pertama dari energi potensial air mengalir menuju turbin kemudian turbin mengubah energi potensial menjadi energi mekanik, turbin satu poros dengan generator memutarkan rotor generator kemudian generator menghasilkan energi listrik. Dari hasil pembangun pembangkit listrik desa, diharapkan dapat meningkatkan kesejahteraan warga kampung Berecek dengan dibangunnya penerangan jalan desa.

\section{DAFTAR PUSTAKA}

Afryantima S, Syukri M 2015 Design and Development of Prototype PLTPH Using Open Flume Turbines Department of Electrical Engineering Syiah Kuala University

Amsary M A, 2017. Report on the Design of Hydroelectric Power Plants Designing Propeller Turbines Department of Energy Conversion Engineering Bandung State Polytechnic

Akhmad S, 2015. Kaplan Water Turbine Simulation on PLTMH in Sampanahan River Magalau Hulu Village Kotabaru Regency Department of Mechanical Engineering Lampung Mangkurat University

Cihanjuang Inti Teknik, 2018. Operation Guide for PLTMH Turbine Propeller Open Flume $1 \mathrm{~kW}$

Dwiyanto V, 2016. Analysis of Micro Hydro Power Plants (MHP) Faculty of Engineering University of Lampung

Joni H, 2016 .Selection of Water Turbines as Generator of $3 \mathrm{~kW}$ in Padayo Village Lubuk Kilangan District Department of Electrical Engineering Padang State Polytechnic

Suryadi A, 2015. Electric Energy \& LAB Power Plant Diktat Indorama Engineering Polytechnic Purwakarta

Suryadi A, 2017. Over frequency Relay Calibration at the Unit 1 Generator Protection System of PT. Java Bali Power Plant Cirata Generation Unit Juteks 4(1) 41-47

Suryadi A, et.al., 2017. Karakteristik Pembebanan Puncak Grid System 500 kV terhadap Arus Eksitasi Pembangkitan. Jurnal Elektra, Vol. 2, Ed. 2 : p. 42-49

Suryadi A, et.al., 2020. Design of a Prime Mover Turbine Propeller Open Flume MicroHydro Electric Power Plant $1 \mathrm{~kW}$, AASEC, Universitas Pendidikan Indonesia

Wibowo H, 2015. Technical and Economic Study of Micro Hydro Power Plant (PLTMH) Planning in Lematang River Pagar Alam City

Yohannes C, 2015. Design of Load-Frequency Control Systems in PLTMH Matano East Luwu Regency Department of Electrical Engineering Faculty of Engineering Hasanuddin University 
SPEKTA

Jurnal Pengabdian Kepada Masyarakat : Teknologi dan Aplikasi

Vol. 1, No. 2, Desember 2020

Halaman ini sengaja dikosongkan 